\section{Úbeda-Baeza: enclave dual del Renacimiento español}

La dimensión patrimonial de las ciudades medias andaluzas es un hecho incuestionable, que pone de relieve la fortaleza del sistema urbano andaluz a lo largo de la historia. Ciudades que han desempeñado las principales funciones de articulación del territorio andaluz, entre ellas Úbeda y Baeza, fueron declaradas Patrimonio de la Humanidad por la UNESCO en julio de 2003. Una declaración que giraba en torno a una palabra clave, la dualidad: un enclave urbano dual, una realidad patrimonial compuesta por dos ciudades que se explican como suma, lo que constituye su verdadera excepcionalidad y el primer caso de una inscripción de este tipo.

Justificar sus valores universales suponía construir un argumento patrimonial unitario e integrador a partir de tres elementos clave de su aportación al Patrimonio Mundial: dualidad urbana excepcional, sin duda; pero también originalidad artística y, a través de ésta, su proyección cultural en Iberoamérica.

Una dualidad urbana complementaria pues en cierto sentido operan como una sola ciudad que domina su territorio inmediato, relación que se hará especialmente intensa durante el Renacimiento coincidiendo con su plena madurez urbana y patrimonial. Una estructura territorial excepcional que no conoce otra situación análoga de dos ciudades de rango equivalente, y tan próximas, que hayan mantenido permanentemente tal situación de paridad.

Esta bicefalia obedece a una dualidad de poderes: en Úbeda, el poder civil, representado por Francisco de los Cobos, influyente Secretario del Emperador Carlos V; y en Baeza, donde el poder del Estado y de la Iglesia serán deudores de su fidelidad desde los primeros tiempos de conquista, circunstancias que explican su complementariedad funcional y su especialización: Úbeda, sede residencial de las principales familias aristocráticas; y Baeza, excepcional centro administrativo, religioso y académico; todo ello en un contexto histórico propio de un territorio de frontera proclive a las libertades y abierto a influencias que favorecieron su espléndido florecimiento cultural y urbano durante el siglo XVI. Dualidad que también se refleja en los modelos de transformación urbana que experimentan cada ciudad, complementarios al mostrar un repertorio de ideas y soluciones del urbanismo renacentis ta, con la originalidad de adaptarlas a una realidad muy distinta de la italiana.

Finalmente, su originalidad artística se debe a una fructífera sintesis entre la tradición medieval de la cantería jiennense y la herencia de sus raíces islámicas, que se enriquecen con la innovación constructiva y la reinterpretación del lenguaje clásico aportados por Andrés de Vandelvira. Una expresión artística que influirá notablemente en numerosas construcciones militares o religiosas como las catedrales de México, Puebla, Mérida, Guadalajara, Oaxaca, Lima o Cuzco, algunas también declaradas Patrimonio Mundial.

Pero la propuesta de declaración no sólo interpretaba sus valores patrimoniales, también pretendía poner en valor sus respectivos centros históricos que en este tipo de ciudades medias pueden ser aún más sensibles a la competencia que sobre ellos ejercen las nuevas áreas de crecimiento. Lograr su reactivación funcional o potenciar su integración con el paisaje han sido objetivos de los Programas de las Áreas de Rehabilitación Concertada que, fruto del impulso de su declaración, actualmente se llevan a cabo en cada ciudad. Un compromiso en la protección y gestión de sus recursos patrimoniales que Úbeda y Baeza deben asumir a la medida de este reconocimiento.

Rufina Fernández Ruiz

Arquitect
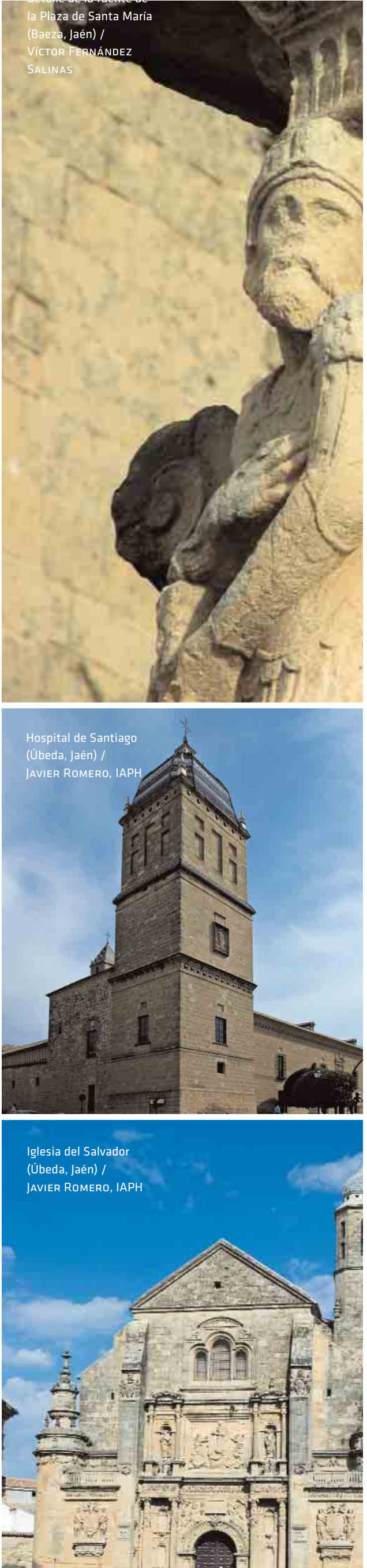